Sharif University of Technology
Scientia Iranica
SCIENTIA
I RAN ICA
http://scientiairanica.sharif.edu

\title{
The effect of buckling and post-buckling behavior of laminated composite plates with rotationally restrained and Pasternak foundation on stacking sequence optimization
}

\author{
S. Farahani ${ }^{\mathrm{a}}$, M. Fathi ${ }^{\mathrm{a}, *}$, and E. Nazarimofrad ${ }^{\mathrm{b}}$ \\ a. Department of Civil Engineering, Razi University, Kermanshah, Iran. \\ b. Department of Civil Engineering, Bu Ali Sina University, Hamedan, Iran.
}

Received 2 May 2020; received in revised form 11 November 2020; accepted 28 December 2020

\author{
KEYWORDS \\ Stacking sequence \\ optimization; \\ Buckling and post- \\ buckling behavior; \\ Rotationally \\ restrained laminated \\ composite plates; \\ Pasternak foundation; \\ Mindlin plate theory.
}

\begin{abstract}
This paper applies stacking sequence optimization for maximizing the buckling load of rotationally restrained laminated composite rectangular plates with different boundary conditions resting on an elastic Pasternak foundation subjected to uniaxial and biaxial in-plane static loads. The Mindlin Plate Theory (MPT), which considers the firstorder shear deformation effect, was used to extract the characteristic equations of the plates under in-plane loading, including plate-foundation interaction. The buckling problem of laminated plates was analyzed by the Rayleigh-Ritz method. The aim of optimization was to maximize the buckling load and post-buckling load capacities using Genetic Algorithm (GA) method, and the design variable was the ply orientation. The results showed that the optimal orientation, $\theta$, of the laminated square plate under biaxial in-plane loading in various conditions was $45^{\circ}$, approximately. The existence of a foundation, clamped boundary conditions, and high aspect ratio led to increase in the optimal orientation.

(C) 2021 Sharif University of Technology. All rights reserved.
\end{abstract}

\section{Introduction}

A large number of polymer matrix laminated composite structures are widely utilized in structural, aeronautics, aerospace, marine engineering, resource tank and automotive industries due to their low weight, high strength, high stiffness, and corrosion properties. For instance, the use of composite laminates in commercial aircraft structures has increased considerably over the past two decades and about $50 \%$ of the Airbus

\footnotetext{
*. Corresponding author.

E-mail addresses: farahani.sina@razi.ac.ir (S. Farahani); fathim@razi.ac.ir (M. Fathi); enazarimofrad@yahoo.com (E. Nazarimofrad)
}

doi: $10.24200 /$ sci. 2020.55883 .4453
A350 XWB structures are made of composite material [1].

Due to this revolutionary tendency adopted by the industry, many researchers have attempted to develop a method for composite laminate structures [2]. Composite structures are generally modeled as plates; thus, identifying their behaviors is crucial to understanding the response of the mentioned structures under extreme loading [3-5]. The variation of plies, thickness, orientation, and stacking sequence makes it easy and possible to achieve the desired mechanical properties such as the in-plane, flexural, and buckling behaviors of composite laminates. Therefore, optimization of composite laminates has recently received much attention [6-9].

There are several methods for obtaining the critical buckling load on isotropic and orthotropic plates. 
Shokrani et al. [10] utilized two-variable refined plate theory to investigate the buckling behavior of doubleorthotropic nanoplates bonded in elastic media under biaxial and uniaxial loading. Shahraki et al. [11] utilized Frobenius solution method to analyze the buckling of the orthotropic rectangular plate under biaxial in-plane loading with non-uniform distribution. Lei et al. [12] studied buckling analysis of functionally graded carbon nanotube-reinforced composite plates employing the first-order shear deformation theory to consider the impacts of rotary inertia and transverse shear deformation. Yu et al. [13] presented a new efficient and precise approach to simulate buckling problems of laminated composite plates with cutouts by combining the isogeometric analysis and the level set. Kheirikhah and Babaghasabha [14] explored buckling behavior of soft core corrugated sandwich plates under uniaxial load. The face sheets were considered as composite laminates and the three-dimensional Finite Element Method (FEM) was utilized to analyze.

To describe the plate-foundation interactions, several types of elastic foundation models have been proposed one of the simplest of which is Winkler model [15]. The model consists of separate independent linear springs that are close to each other. This kind of foundation is a one-parameter model in which only springs in the loaded area are affected. Farahani and Mohebkhah [16] utilized Winkler's model for developing their models to investigate the sensitivity of Direct Displacement-Based (DDB) designed frames to the effect of foundation flexibility. Pasternak [17] added a shear layer to Winkler's model to improve the model. The layer establishes a shear interaction between the independent springs. The model is broadly utilized to illustrate the mechanical behavior of structurefoundation interactions. Nazarimofrad et al. [18,19] conducted buckling analysis of an orthotropic rectangular Mindlin plate resting on an elastic Pasternak foundation. They utilized Rayleigh-Ritz method to solve the governing equations based on the MindlinReissner plate theory.

Guo et al. [20] proposed a deep collocation method based on a feedforward Deep Neural Network (DNN) to solve the formed partial differential equations of buckling analysis plates. Samaniego et al. [21] developed an energy approach based on DNN-based approximation method to solve the formed partial differential equations. The results of computational mechanics illustrated the capabilities of the proposed method. However, due to various coupled parameters of composite plates, the previous work by Shokrollahi and Shafaghat [2] showed that using the Rayleigh-Ritz based method could be a reliable and accurate method to develop the analysis method of composite laminates. Akhavan et al. [22] presented exact solutions for the buckling analysis of rectangular isotropic plates located on Pasternak foundation with various types of boundary conditions subjected to uniformly and linearly in-plane loadings. Golmakani and Rezatalab [23] investigated the buckling analysis of orthotropic graphene sheets embedded within elastic medium by Pasternak model under non-uniform biaxial loading. The first-order shear deformation theory and differential quadrature method were used to derive the nanoplate equilibrium equations and solve the governing equations in various boundary conditions, respectively.

In the case of optimizing the maximum buckling load of laminated composite plates, the aim is often achieved by changing the stacking sequence, ply orientation, and ply thickness as design variables. Many researchers have studied the problem of optimal design of composite laminates. Topal and Uzman [24] managed to optimize laminated composite plates with simple supports subject to in-plane loads. The objective function was to maximize the buckling load capacity of composite plates by changing the design variable (ply orientation). The first-order shear deformation theory was used for the finite element analysis. Genetic Algorithm (GA) is one of the first effective approaches to the optimization of composite laminates. Le-Manh and Lee [25] obtained maximum bending, buckling, and post-buckling capacities of imperfect laminated composite plates by GA and NURBS-based finite element iso-geometric analysis. The fiber orientation was the design variable. Vu-Bac et al. [26] proposed a new method to develop material and geometric nonlinearities for inverse analysis. The NURBS-based finite element analysis was also utilized to capture the stable shape changes. Vosoughi et al. [27] maximized the buckling load of thick laminated composite plates by optimizing the stacking sequence of plates. To this end, they employed the finite element, GA, and particle swarm optimization methods. Ehsani and Rezaeepazhand [28] employed GA to optimize the stacking sequence and pattern composition of the laminated grid plate. The objective function was the buckling load, while the design variables were the pattern and orientation of the grid layer. Ritz method, as a classical laminated plate theory, was considered to determine the buckling loads.

The success attributed to GA has led to much research on the application of other approaches to the optimization of laminated composites. Using the permutation search algorithm and considering the ply orientation as a design variable, Jing [29] performed optimization for obtaining the maximum of buckling load. de Almeida [30] maximized the bucking load of a symmetric laminated plate in stacking sequence optimization using the harmony search algorithm. They indicated that although harmony search algorithm was less reliable than a special version of GA, it would be more effective than other metaheuristic methods. Kaveh et 
al. [31] optimized the stacking sequence of laminated composites using the biogeography-based optimization algorithm to maximize the buckling load of symmetric composite laminated plates. de Almeida [32] proposed a new optimization method for composite structures based on harmony search algorithm. The results of this study showed that composite structures could be optimized better by the harmony search algorithm than other previous approaches. To maximize load capacity and improve the dynamic performance of laminated composite plates, Serhat and Basdogan [33] developed a multi-objective optimization method. Atri and Shojaee [34] developed a method for dealing with the buckling response of laminated composite plates using coupling of truncated hierarchical B-splines methods. The results of numerical cases considering different fiber orientations of laminated plates and various geometrical shapes pointed to the high accuracy of all test models. Recently, Nguyen et al. [35] proposed a new optimization method based on the gradientbased interior point algorithm for increasing the biaxial bulking load capacity of laminated composite plates. Jing et al. [36] employed an Enhanced Permutation Search (EPS) algorithm for simply supported orthotropic plates to maximize the buckling load. The obtained results of EPS algorithm showed that the computational cost decreased dramatically, compared to traditional algorithms. In spite of several researches on the optimization of laminated composite plates for obtaining the maximum of buckling load, to the best of our knowledge, there is no research conducted on optimization of laminated composite plates considering routinely restrained and elastic Pasternak foundation effects.

The main objective of this study is to apply GA to the buckling optimization of a rotationally restrained composite plate resting on an elastic Pasternak foundation. To solve the problems in which the objective function is discontinuous, non-differentiable, stochastic, or highly nonlinear, GA can be utilized, which is categorized as search heuristics. GA is a global search algorithm that uses a population of designs instead of a single point in the design space; hence, the probability of finding the global optimum in the optimization process is high and local optimum points need to be avoided [37]. The optimization implementation is done using GA [38] and the Toolbox of MATLAB software [39]. The analysis procedure is based on the Mindlin Plate Theory (MPT) considering the first-order shear deformation effects including the plate-foundation interaction. The buckling problem of the laminated plate is analyzed using Rayleigh-Ritz method. The aim of optimization is to maximize the buckling load capacity, while ply orientation is taken as a design variable.

\section{Theoretical formulation}

Consider a rectangular laminated composite plate with the constant thickness of $h$ and the in-plane dimensions of $a$ and $b$ resting on an elastic Pasternak foundation, as illustrated in Figure 1. Two of boundary conditions are rotationally restrained and the other two boundaries are subject to simply supported conditions. By ignoring the axial in-plan deformations, the governing strain energy equation of the laminated composite plate resting on the Pasternak foundation can be written by Eq. (1) as shown in Box I [40], where $w_{0}, \psi_{x}$, and $\psi_{y}$ are the transverse displacement, rotational displacement about $x$ axe, and rotational displacement about $y$ axe, respectively. Furthermore, $k_{w}$ and $k_{s}$ are the lateral stiffnesses of resistant elements of foundation in vertical and shear directions, respectively. Indeed, these two parameters define the Pasternak foundation, as shown in Figure 1(a). Parameter $k$ is defined as a shear correction coefficient considered as $5 / 6$. Considering the classical plate theory for the laminated composite structure, $D$ is defined as the flexural stiffness matrix:

$$
\begin{aligned}
& D=\left[\begin{array}{lll}
D_{11} & D_{12} & D_{16} \\
D_{21} & D_{22} & D_{26} \\
D_{16} & D_{26} & D_{66}
\end{array}\right], \\
& D_{i j}=\sum_{k=1}^{N_{L}} \int_{z_{k}}^{z_{k+1}} \bar{Q}_{i j}^{(k)} z^{2} d z \quad(i, j)=(1,2,6) .
\end{aligned}
$$

$A_{i j}$ is the extensional stiffness matrix as follows:

$$
\Pi_{i}=\frac{1}{2} \int_{0}^{b} \int_{0}^{a}\left[\begin{array}{l}
D_{11}\left(\frac{d \psi_{x}}{d x}\right)^{2}+2 D_{12} \frac{d \psi_{y}}{d y} \frac{d \psi_{x}}{d x}+2 D_{16} \frac{d \psi_{x}}{d x}\left(\frac{d \psi_{x}}{d y}+\frac{d \psi_{y}}{d x}\right) \\
+D_{22}\left(\frac{d \psi_{y}}{d y}\right)^{2}+2 D_{26} \frac{d \psi_{y}}{d y}\left(\frac{d \psi_{x}}{d y}+\frac{d \psi_{y}}{d x}\right)+D_{66}\left(\frac{d \psi_{x}}{d y}+\frac{d \psi_{y}}{d x}\right)^{2} \\
+K A_{44}\left(\frac{d w_{0}}{d y}+\psi_{y}\right)^{2}+K A_{55}\left(\frac{d w_{0}}{d x}+\psi_{x}\right)^{2} \\
+2 K A_{45}\left(\frac{d w_{0}}{d y}+\psi_{y}\right)\left(\frac{d w_{0}}{d x}+\psi_{x}\right)+k_{w} w_{0}^{2}+k_{s}\left(\left(\frac{d w_{0}}{d x}\right)^{2}+\left(\frac{d w_{0}}{d y}\right)^{2}\right.
\end{array}\right] d x d y
$$




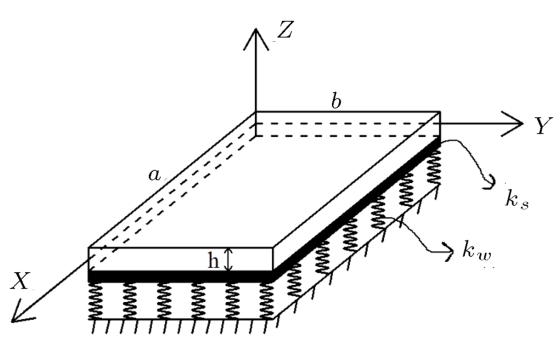

(a) Rectangular plate on Pasternak foundation

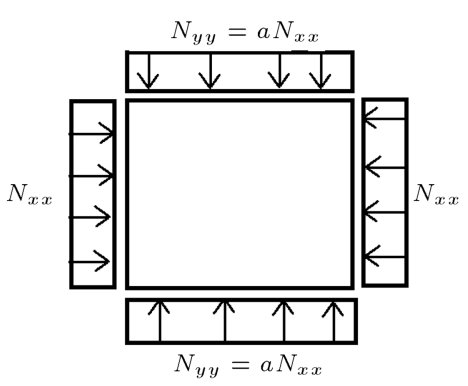

(b) In-plane loading

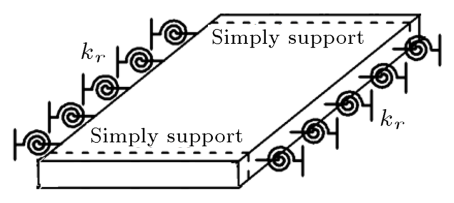

(c) Boundary conditions

Figure 1. Rectangular laminated composite plate resting on an elastic Pasternak foundation.

$$
A_{i j}=\sum_{k=1}^{N_{L}} \int_{z_{k}}^{z_{k+1}} \bar{Q}_{i j}^{(k)} d z \quad(i, j)=(4,5),
$$

where $\bar{Q}_{i j}^{(k)}(1,2,4,5,6)$ are the transformed stiffness coefficients of the $k$ th layer of the plate, and $z_{k}$ and $z_{k+1}$ are the coordinates of the lower and upper surfaces of the $k$ th layer of the plate along $z$ direction, respectively.

The external potential energy $\Pi_{e}$ can be written below in which in-plane applied loads are denoted by $N_{x x}^{0}$ and $N_{y y}^{0}$ :

$$
\Pi_{e}=-\frac{1}{2} \int_{0}^{b} \int_{0}^{a} N_{x x}^{0}\left(\frac{d w_{0}}{d x}\right)^{2}+N_{y y}^{0}\left(\frac{d w_{0}}{d y}\right)^{2} d x d y
$$

Considering that $k_{r}$, as a stiffness value, could be stored in a system as shown in Figure 1(c), the restraining energy $\Pi_{s}$ can be calculated as follows:

$$
\Pi_{s}=\frac{k_{r}}{2} \int_{0}^{a}\left[\psi_{y}^{2}(y=0)+\psi_{y}^{2}(y=b)\right] d x
$$

Then, the total elastic potential $\Pi$ of the laminated composite system would be as follows:

$$
\Pi=\Pi_{i}+\Pi_{e}+\Pi_{s} .
$$

Using the appropriate shape function into each term of Eq. (6) (i.e., Eqs. (1), (4), and (5)), the eigenvalue problem of buckling could be solved in conjunction with the Rayleigh-Ritz method. All boundary conditions should be satisfied by shape functions. The shape functions for $w_{0}, \psi_{x}$, and $\psi_{y}$ are considered in the following equations:

$$
\begin{aligned}
& w_{0}=W w_{1}(x) w_{2}(y), \\
& \psi_{x}=X \psi_{x 1}(x) \psi_{x 2}(y), \\
& \psi_{y}=Y \psi_{y 1}(x) \psi_{y 2}(y)
\end{aligned}
$$

where $w_{1}(x), w_{2}(y), \psi_{x 1}(x), \psi_{x 2}(y), \psi_{y 1}(x)$, and $\psi_{y 2}(y)$ are the shape functions based on satisfaction of boundary conditions. The unknown parameters $W$, $X$, and $Y$ remain as uncalculated parameters due to buckling theory [40]. By substituting Eq. (7) into Eq. (6), the final form of elastic potential energy can be written as follows:

$$
\begin{aligned}
& \Pi=\frac{1}{2} D_{11} X^{2} \int_{0}^{a}\left(\frac{d \psi_{x 1}}{d x}\right)^{2} d x \int_{0}^{b} \psi_{x 2}^{2} d y \\
& +D_{12} X Y \int_{0}^{a} \frac{d \psi_{x 1}}{d x} \psi_{y 1} d x \int_{0}^{b} \frac{d \psi_{y 2}}{d y} \psi_{x 2} d \\
& +D_{16} X^{2} \int_{0}^{a} \frac{d \psi_{x 1}}{d x} \psi_{x 1} d x \int_{0}^{b} \frac{d \psi_{x 2}}{d y} \psi_{x 2} d y \\
& +D_{16} X Y \int_{0}^{a} \frac{d \psi_{x 1}}{d x} \frac{d \psi_{y 1}}{d x} d x \int_{0}^{b} \psi_{x 2} \psi_{y 2} d \\
& +\frac{1}{2} D_{22} Y^{2} \int_{0}^{a} \psi_{y 1}^{2} d x \int_{0}^{b}\left(\frac{d \psi_{y 2}}{d y}\right)^{2} d y \\
& +D_{26} X Y \int_{0}^{a} \psi_{x 1} \psi_{y 1} d x \int_{0}^{b} \frac{d \psi_{x 2}}{d y} \frac{d \psi_{y 2}}{d y} d y \\
& +D_{26} Y^{2} \int_{0}^{a} \frac{d \psi_{y 1}}{d x} \psi_{y 1} d x \int_{0}^{b} \frac{d \psi_{y 2}}{d y} \psi_{y 2} d y \\
& +\frac{1}{2} D_{66} X^{2} \int_{0}^{a} \psi_{x 1}^{2} d x \int_{0}^{b}\left(\frac{d \psi_{x 2}}{d y}\right)^{2} d y \\
& +D_{66} X Y \int_{0}^{a} \frac{d \psi_{y 1}}{d x} \psi_{x 1} d x \int_{0}^{b} \frac{d \psi_{x 2}}{d y} \psi_{y 2} d y \\
& +\frac{1}{2} D_{66} Y^{2} \int_{0}^{a}\left(\frac{d \psi_{y 1}}{d x}\right)^{2} d x \int_{0}^{b} \psi_{y 2}^{2} d y \\
& +\frac{1}{2} K A_{44} W^{2} \int_{0}^{a} w_{1}^{2} d x \int_{0}^{b}\left(\frac{d w_{2}}{d y}\right)^{2} d y \\
& +K A_{44} W Y \int_{0}^{a} w_{1} \psi_{y 1} d x \int_{0}^{b} \frac{d w_{2}}{d y} \psi_{y 2} d y \\
& +\frac{1}{2} K A_{44} Y^{2} \int_{0}^{a} \psi_{y 1}^{2} d x \int_{0}^{b} \psi_{y 2}^{2} d y
\end{aligned}
$$




$$
\begin{aligned}
& +K A_{45} W^{2} \int_{0}^{a} w_{1} \frac{d w_{1}}{d x} d x \int_{0}^{b} w_{2} \frac{d w_{2}}{d y} d y \\
& +K A_{45} W Y \int_{0}^{a} \frac{d w_{1}}{d x} \psi_{y 1} d x \int_{0}^{b} w_{2} \psi_{y 2} d y \\
& +K A_{45} W X \int_{0}^{a} w_{1} \psi_{x 1} d x \int_{0}^{b} \frac{d w_{2}}{d y} \psi_{x 2} d y \\
& +K A_{45} X Y \int_{0}^{a} \psi_{x 1} \psi_{y 1} d x \int_{0}^{b} \psi_{x 2} \psi_{y 2} d y \\
& +\frac{1}{2} K A_{55} W^{2} \int_{0}^{a}\left(\frac{d w_{1}}{d x}\right)^{2} d x \int_{0}^{b} w_{2}^{2} d y \\
& +K A_{55} W X \int_{0}^{a} \frac{d w_{1}}{d x} \psi_{x 1} d x \int_{0}^{b} w_{2} \psi_{x 2} d y \\
& +\frac{1}{2} k_{r} Y^{2} \int_{0}^{a} \psi_{y 1}^{2} d x\left[\psi_{y 2}^{2}(y=0)+\psi_{y 2}^{2}(y=b)\right] \\
& +\frac{1}{2} K A_{55} X^{2} \int_{0}^{a} \psi_{x 1}^{2} d x \int_{0}^{b} \psi_{x 2}^{2} d y \\
& +\frac{1}{2} N_{x x}^{0} W^{2} \int_{0}^{a}\left(\frac{d w_{1}}{d x}\right)^{2} d x \int_{0}^{b} w_{2}^{2} d y+w_{2}^{2} d y \\
& +\frac{1}{2} k_{w} W^{2} \int_{0}^{a} w_{1}^{2} d x \int_{0}^{b} w_{2}^{2} d y+k_{s}^{2} w_{1}^{2} d x \int_{0}^{b}\left(\frac{d w_{2}}{d y}\right)^{2} d y \\
&
\end{aligned}
$$

In Eq. (8), the shape functions $w_{1}(x), w_{2}(y), \psi_{x 1}(x)$, $\psi_{x 2}(y), \psi_{y 1}(x)$, and $\psi_{y 2}(y)$ are subjected to integration with respect to $x$ or $y$. The integrals must be solvable because the shape functions are known. The following parameters are introduced and written in Eq. (9) for the sake of simplicity.

$$
\begin{aligned}
& I_{1}=\int_{0}^{a}\left(\frac{d \psi_{x 1}}{d x}\right)^{2} d x, \quad J_{1}=\int_{0}^{b} \psi_{x 2}^{2} d y, \\
& I_{2}=\int_{0}^{a} \frac{d \psi_{x 1}}{d x} \psi_{y 1} d x, J_{2}=\int_{0}^{b} \frac{d \psi_{y 2}}{d y} \psi_{x 2} d y, \\
& I_{3}=\int_{0}^{a} \frac{d \psi_{x 1}}{d x} \psi_{x 1} d x, \quad J_{3}=\int_{0}^{b} \frac{d \psi_{x 2}}{d y} \psi_{x 2} d y, \\
& I_{4}=\int_{0}^{a} \frac{d \psi_{x 1}}{d x} \frac{d \psi_{y 1}}{d x} d x, \quad J_{4}=J_{17}=\int_{0}^{b} \psi_{x 2} \psi_{y 2} d y,
\end{aligned}
$$

$$
\begin{aligned}
& I_{5}=I_{13}=\int_{0}^{a} \psi_{y 1}^{2} d x, \quad J_{5}=\int_{0}^{b}\left(\frac{d \psi_{y 2}}{d y}\right)^{2} d y, \\
& I_{6}=I_{17}=\int_{0}^{a} \psi_{x 1} \psi_{y 1} d x, \quad J_{6}=\int_{0}^{b} \frac{d \psi_{x 2}}{d y} \frac{d \psi_{y 2}}{d y} d y \\
& I_{7}=\int_{0}^{a} \frac{d \psi_{y 1}}{d x} \psi_{y 1} d x, \quad J_{7}=\int_{0}^{b} \frac{d \psi_{y 2}}{d y} \psi_{y 2} d y, \\
& I_{8}=I_{20}=\int_{0}^{a} \psi_{x 1}^{2} d x, \quad J_{8}=\int_{0}^{b}\left(\frac{d \psi_{x 2}}{d y}\right)^{2} d y, \\
& I_{9}=\int_{0}^{a} \frac{d \psi_{y 1}}{d x} \psi_{x 1} d x, \quad J_{9}=\int_{0}^{b} \frac{d \psi_{x 2}}{d y} \psi_{y 2} d y, \\
& I_{10}=\int_{0}^{a}\left(\frac{d \psi_{y 1}}{d x}\right)^{2} d x, \quad J_{10}=J_{13}=\int_{0}^{b} \psi_{y 2}^{2} d y, \\
& I_{11}=\int_{0}^{a} w_{1}^{2} d x, \quad J_{11}=\int_{0}^{b}\left(\frac{d w_{2}}{d y}\right)^{2} d y \\
& I_{12}=\int_{0}^{a} w_{1} \psi_{y 1} d x, \quad J_{12}=\int_{0}^{b} \frac{d w_{2}}{d y} \psi_{y 2} d y, \\
& I_{18}=\int_{0}^{a}\left(\frac{d w_{1}}{d x}\right)^{2} d x, \quad J_{18}=\int_{0}^{b} w_{2}^{2} d y \\
& I_{14}=\int_{0}^{a} w_{1} \frac{d w_{1}}{d x} d x, \quad J_{14}=\int_{0}^{b} w_{2} \frac{d w_{2}}{d y} d y, \\
& I_{15}=\int_{0}^{a} \frac{d w_{1}}{d x} \psi_{y 1} d x, \quad J_{15}=\int_{0}^{b} w_{2} \psi_{y 2} d y, \\
& I_{16}=\int_{0}^{a} w_{1} \psi_{x 1} d x, \quad J_{16}=\int_{0}^{b} \frac{d w_{2}}{d y} \psi_{x 2} d y, \\
& I_{19}=\int_{0}^{a} \frac{d w_{1}}{d x} \psi_{x 1} d x, \quad J_{19}=\int_{0}^{b} w_{2} \psi_{x 2} d y, \\
& C_{1 \text { rot }}=\psi_{y 2}^{2}(y=0), \quad C_{2 \text { rot }}=\psi_{y 2}^{2}(y=b) .
\end{aligned}
$$

By considering the above defined parameters, Eq. (8) can be rewritten as follows:

$$
\begin{aligned}
\Pi= & \frac{1}{2} D_{11} X^{2} I_{1} J_{1}+D_{12} X Y I_{2} J_{2}+D_{16} X^{2} I_{3} J_{3} \\
& +D_{16} X Y I_{4} J_{4}+\frac{1}{2} D_{22} Y^{2} I_{5} J_{5}+D_{26} X Y I_{6} J_{6} \\
& +D_{26} Y^{2} I_{7} J_{7}+\frac{1}{2} D_{66} X^{2} I_{8} J_{8}+D_{66} X Y I_{9} J_{9} \\
& +\frac{1}{2} D_{66} Y^{2} I_{10} J_{10}+\frac{1}{2} K A_{44} W^{2} I_{11} J_{11} \\
& +K A_{44} W Y I_{12} J_{12}+\frac{1}{2} K A_{44} Y^{2} I_{5} J_{10}
\end{aligned}
$$




$$
\begin{aligned}
& +K A_{45} W^{2} I_{14} J_{14}+K A_{45} W Y I_{15} J_{15} \\
& +K A_{45} W X I_{16} J_{16}+K A_{45} X Y I_{6} J_{4} \\
& +\frac{1}{2} K A_{55} W^{2} I_{18} J_{18}+K A_{55} W X I_{19} J_{19} \\
& +\frac{1}{2} K A_{55} X^{2} I_{8} J_{1}+\frac{1}{2} k_{w} W^{2} I_{11} J_{18} \\
& +\frac{1}{2} k_{s} W^{2} I_{18} J_{18}+\frac{1}{2} k_{s} W^{2} I_{11} J_{11} \\
& -\frac{1}{2} N_{x x}^{0} W^{2} I_{18} J_{18}-\frac{1}{2} N_{y y}^{0} W^{2} I_{11} J_{11}, \\
& +\frac{1}{2} k_{r} Y^{2} I_{5}\left(C_{1 \text { rot }}+C_{2 \text { rot }}\right) .
\end{aligned}
$$

When the elastic potential energy $\Pi$ achieves a stationary value, the buckling of laminate plates occurs. Indeed, the first variation of $\delta \Pi$ vanishes: $\delta \Pi=0$. According to Eq. (10), the only variable quantities in $\Pi$ are constants $W, X$, and $Y$, i.e., $\Pi=\Pi(X . Y . Z)$. Thus, the main buckling condition $\delta \Pi=0$ decreases to the well-known Ritz equations as follows:

$$
\begin{aligned}
& \frac{d \Pi}{d W}=0 \Rightarrow \frac{d \Pi}{d W}=\left(K A_{44} I_{11} J_{11}+2 K A_{45} I_{14} J_{14}\right. \\
& +K A_{55} I_{18} J_{18}+k_{w} I_{11} J_{18}+k_{s} I_{18} J_{18} \\
& \left.+k_{s} I_{11} J_{11}-N_{x x}^{0} I_{18} J_{18}-N_{y y}^{0} I_{11} J_{11}\right) W \\
& +\left(K A_{45} I_{16} J_{16}+K A_{55} I_{19} J_{19}\right) X \\
& +\left(K A_{44} I_{12} J_{12}+K A_{45} I_{15} J_{15}\right) Y=0, \\
& \frac{d \Pi}{d X}=0 \Rightarrow \frac{d \Pi}{d X}=\left(K A_{45} I_{16} J_{16}+K A_{55} I_{19} J_{19}\right) W \\
& +\left(D_{11} I_{1} J_{1}+2 D_{16} I_{3} J_{3}+D_{66} I_{8} J_{8}\right. \\
& \left.+K A_{55} I_{8} J_{1}\right) X+\left(D_{12} I_{2} J_{2}+D_{16} I_{4} J_{4}\right. \\
& \left.+D_{26} I_{6} J_{6}+D_{66} I_{9} J_{9}+K A_{45} I_{6} J_{4}\right) Y=0, \\
& \frac{d \Pi}{d Y}=0 \Rightarrow \frac{d \Pi}{d Y}=\left(K A_{44} I_{12} J_{12}+K A_{45} I_{15} J_{15}\right) W \\
& +\left(D_{12} I_{2} J_{2}+D_{16} I_{4} J_{4}+D_{26} I_{6} J_{6}+D_{66} I_{9} J_{9}\right. \\
& \left.+K A_{45} I_{6} J_{4}\right) X+\left(D_{22} I_{5} J_{5}+2 D_{26} I_{7} J_{7}\right.
\end{aligned}
$$

$$
\begin{aligned}
& +D_{66} I_{10} J_{10}+K A_{44} I_{5} J_{10}+k_{r} I_{5}\left(C_{1 \text { rot }}\right. \\
& \left.\left.+C_{2 \text { rot }}\right)\right) Y=0 .
\end{aligned}
$$

Upon defining the following parameters, we have:

$$
\begin{aligned}
\lambda_{11}= & K A_{44} I_{11} J_{11}+2 K A_{45} I_{14} J_{14}+K A_{55} I_{18} J_{18} \\
& +k_{w} I_{11} J_{18}+k_{s} I_{18} J_{18}+k_{s} I_{11} J_{11}, \\
\lambda_{12}= & K A_{45} I_{16} J_{16}+K A_{55} I_{19} J_{19}, \\
\lambda_{13}= & K A_{44} I_{12} J_{12}+K A_{45} I_{15} J_{15}, \\
\lambda_{22}= & D_{11} I_{1} J_{1}+2 D_{16} I_{3} J_{3}+D_{66} I_{8} J_{8}+K A_{55} I_{8} J_{1}, \\
\lambda_{23}= & \left(D_{12} I_{2} J_{2}+D_{16} I_{4} J_{4}+D_{26} I_{6} J_{6}+D_{66} I_{9} J_{9}\right. \\
& +K A_{45} I_{6} J_{4}, \\
\lambda_{33}= & D_{22} I_{5} J_{5}+2 D_{26} I_{7} J_{7}+D_{66} I_{10} J_{10}+K A_{44} I_{5} J_{10} \\
& +k_{r} I_{5}\left(C_{1 \text { rot }}+C_{2 \text { rot }}\right), \\
\bar{\lambda}_{11}= & I_{18} J_{18}+\alpha I_{11} J_{11}, \\
N_{y y}^{0}= & \alpha N_{x x}^{0} .
\end{aligned}
$$

The equation system (12) can be written in a matrix form as:

$$
\left[\begin{array}{ccc}
\lambda_{11}-N_{c r}^{0} \bar{\lambda}_{11} & \lambda_{12} & \lambda_{13} \\
\lambda_{21} & \lambda_{22} & \lambda_{23} \\
\lambda_{31} & \lambda_{32} & \lambda_{33}
\end{array}\right]\left\{\begin{array}{l}
W \\
X \\
Y
\end{array}\right\}=\left\{\begin{array}{l}
0 \\
0 \\
0
\end{array}\right\}
$$

The coefficient matrix determinant of the equation system (13) must be equal to zero given no non-trivial solution has been used. Therefore, the closed form of the buckling load $N_{c r}^{0}$ is obtained by Eq. (14) as shown in Box II. In addition, non-dimensional buckling load, non-dimensional Winkler foundation parameter, and non-dimensional Pasternak foundation parameter are present respectively as follows:

$$
\begin{aligned}
& \bar{N}_{c r}^{0}=N_{c r}^{0} \frac{b^{2}}{E_{2} \cdot h^{3}}, \quad K_{W}=k_{w} \frac{b^{4}}{E_{2} \cdot h^{3}}, \\
& K_{S}=k_{s} \frac{b^{2}}{E_{2} \cdot h^{3}} .
\end{aligned}
$$

According to Kuehn et al. [40], the following shape functions can be utilized for the plate with a simple support at the two opposite edges and rotationally restrained conditions on the other two edges. 


$$
N_{c r}^{0}=\frac{\lambda_{11}\left(\lambda_{22} \lambda_{33}-\lambda_{23} \lambda_{32}\right)-\lambda_{21}\left(\lambda_{12} \lambda_{33}-\lambda_{13} \lambda_{32}\right)+\lambda_{31}\left(\lambda_{12} \lambda_{23}-\lambda_{13} \lambda_{22}\right)}{\bar{\lambda}_{11}\left(\lambda_{22} \lambda_{33}-\lambda_{23} \lambda_{32}\right)} .
$$

Box II

$$
\begin{aligned}
& w_{1}(x)=\sin \left(\frac{m \pi x}{a}\right) \\
& w_{2}(y)=(1-\beta) \sin \left(\frac{\pi y}{b}\right)+\beta \frac{1}{2}\left[1-\cos \left(2 \frac{\pi y}{b}\right)\right] \\
& \psi_{x 1}(x)=\cos \left(\frac{m \pi x}{a}\right) \\
& \psi_{x 2}(y)=(1-\beta) \sin \left(\frac{\pi y}{b}\right)+\beta \frac{1}{2}\left[1-\cos \left(2 \frac{\pi y}{b}\right)\right] \\
& \psi_{y 1}(x)=\sin \left(\frac{m \pi x}{a}\right), \\
& \psi_{y 2}(y)=(1-\beta) \cos \left(\frac{\pi y}{b}\right)+\beta \sin \left(2 \frac{\pi y}{b}\right) .
\end{aligned}
$$

In Eq. (16), the factor $\beta$ can be calculated by interpolating between the two models of a simply supported laminate plate (i.e., $k_{r}=0$ ) and a fully supported laminate plate (i.e., $k_{r} \rightarrow \infty$ ). These two models correspond to $\beta=0$ and $\beta=1$, respectively. Therefore, the factor $\beta$ can be obtained as follows:

$$
\beta=\frac{k_{r} b}{2 D_{22} \pi+k_{r} b} \text {. }
$$

\section{Results and discussion}

This section is divided into two subsections. The first and second parts deal with the validation of the formulas and the desired optimization, respectively.

\subsection{Modeling and validation}

In the first subsection, to validate the presented method, the non-dimensional buckling load factors of the laminated plates under two types of loading (uniaxial and biaxial) are evaluated with previous works. The material properties of laminated plates are considered as follows:

$$
\begin{aligned}
& \frac{E_{1}}{E_{2}}=40, \quad \frac{G_{12}}{E_{2}}=\frac{G_{13}}{E_{2}}=0.6, \\
& \frac{G_{23}}{E_{2}}=0.5, \quad \nu_{12}=\nu_{13}=0.25 .
\end{aligned}
$$

It is assumed that the ratio of the length of $b$ to the thickness of the plate is $b / h=10$. Table 1 shows the non-dimensional buckling load factors (uniaxial and biaxial) of a symmetrically laminated composite plate with 3 plies [0/90/0] on Winkler and Pasternak foundations at different values of aspect ratios for the present method, as compared with the works of Setoodeh and Karami [41] and Xiang et al. [42]. The results point to a good correlation between the findings of the present method and the related literature. The results in Table 1 indicate that the developed method is reliable enough to be utilized in measuring nondimensional buckling load factors.

To ensure revalidation of the results using Ref. [43], the optimal stacking sequence of several states is investigated with the above-mentioned material. It is assumed that the aspect ratios of the thickness of the plate are $b / h=10$ and $b / h=30$. Table 2

\begin{tabular}{|c|c|c|c|c|c|c|c|c|}
\hline \multirow[b]{2}{*}{$a / b$} & \multirow[b]{2}{*}{$\boldsymbol{K}_{W}$} & \multirow[b]{2}{*}{$\boldsymbol{K}_{S}$} & \multicolumn{3}{|c|}{ Uniaxial: $\alpha=0$} & \multicolumn{3}{|c|}{ Biaxial: $\alpha=1$} \\
\hline & & & $\begin{array}{c}\text { Setoodeh and } \\
\text { Karami } \\
{[41]}\end{array}$ & $\begin{array}{c}\text { Xiang et al. } \\
{[42]}\end{array}$ & $\begin{array}{c}\text { Present } \\
\text { study }\end{array}$ & $\begin{array}{c}\text { Setoodeh and } \\
\text { Karami } \\
{[41]}\end{array}$ & $\begin{array}{c}\text { Xiang et al. } \\
{[42]}\end{array}$ & $\begin{array}{c}\text { Present } \\
\text { study }\end{array}$ \\
\hline \multirow{3}{*}{1} & 0 & 0 & 22.234 & 22.315 & 22.312 & 9.942 & 10.202 & 10.520 \\
\hline & 100 & 0 & 32.235 & 32.447 & 32.439 & 11.923 & 12.228 & 12.235 \\
\hline & 100 & 10 & 49.226 & 50.751 & 50.743 & 21.866 & 22.228 & 22.237 \\
\hline \multirow{3}{*}{2} & 0 & 0 & 16.424 & 16.434 & 16.426 & 3.269 & 3.286 & 3.295 \\
\hline & 100 & 0 & 32.354 & 32.447 & 32.426 & 9.345 & 9.590 & 9.621 \\
\hline & 100 & 10 & 49.039 & 49.266 & 49.251 & 19.140 & 19.590 & 19.622 \\
\hline
\end{tabular}
shows the non-dimensional buckling load factors of a symmetrically laminated composite plate with 8 plies $[\theta /-\theta / \cdots]$ without foundations at different values of aspect ratios. The results are compared with the present method, pointing to a good correlation between the present method and the mentioned reference. For example, to validate the formulas, an angle-ply composite plate made of T300/5208 graphite/epoxy layers

Table 1. Uniaxial and biaxial non-dimensional buckling load factors of a laminated composite. 
Table 2. Non-dimensional buckling load factors of a symmetrically laminated composite.

\begin{tabular}{|c|c|c|c|c|c|c|c|c|c|}
\hline \multirow[b]{2}{*}{$a / h$} & \multicolumn{3}{|c|}{$a / b=1.0$} & \multicolumn{3}{|c|}{$a / b=1.5$} & \multicolumn{3}{|c|}{$a / b=2.0$} \\
\hline & $\begin{array}{l}\text { Optimal } \\
\text { angle }\end{array}$ & $\begin{array}{c}\text { Kam and } \\
\text { Chang } \\
{[43]} \\
\end{array}$ & $\begin{array}{c}\text { Present } \\
\text { study }\end{array}$ & $\begin{array}{l}\text { Optimal } \\
\text { angle }\end{array}$ & $\begin{array}{c}\text { Kam and } \\
\text { Chang } \\
{[43]} \\
\end{array}$ & $\begin{array}{c}\text { Present } \\
\text { study }\end{array}$ & $\begin{array}{l}\text { Optimal } \\
\text { angle }\end{array}$ & $\begin{array}{c}\text { Kam and } \\
\text { Chang } \\
{[43]}\end{array}$ & $\begin{array}{c}\text { Present } \\
\text { study }\end{array}$ \\
\hline 10 & 40 & 36.85 & 34.26 & 23 & 21.17 & 20.03 & 13 & 12.45 & 12.09 \\
\hline 30 & 45 & 59.06 & 56.77 & 43 & 60.17 & 57.36 & 32 & 48.86 & 46.14 \\
\hline
\end{tabular}

Table 3. The results of buckling analysis.

\begin{tabular}{cccccc}
\hline Example & $\begin{array}{c}\boldsymbol{a} \\
(\mathbf{m m})\end{array}$ & $\begin{array}{c}\boldsymbol{b} \\
(\mathbf{m m})\end{array}$ & $\begin{array}{c}\boldsymbol{k}_{\boldsymbol{r}} \\
(\mathbf{N . m m})\end{array}$ & $\begin{array}{c}\text { Programming results } \\
\boldsymbol{N}_{\boldsymbol{x} \boldsymbol{x}}(\mathbf{N} / \mathbf{m m})\end{array}$ & $\begin{array}{c}\text { ABAQUS [44] results } \\
\boldsymbol{N}_{\boldsymbol{x} \boldsymbol{x}}(\mathbf{N} / \mathbf{m m})\end{array}$ \\
\hline 1 & 500 & 500 & 0 & 17.7 & 18.4 \\
2 & 3000 & 500 & 0 & 3.50 & 3.69 \\
3 & 500 & 500 & $1 \times 10^{9}$ & 20.00 & 21.95 \\
4 & 3000 & 500 & $1 \times 10^{9}$ & 9.59 & 10.72 \\
\hline
\end{tabular}
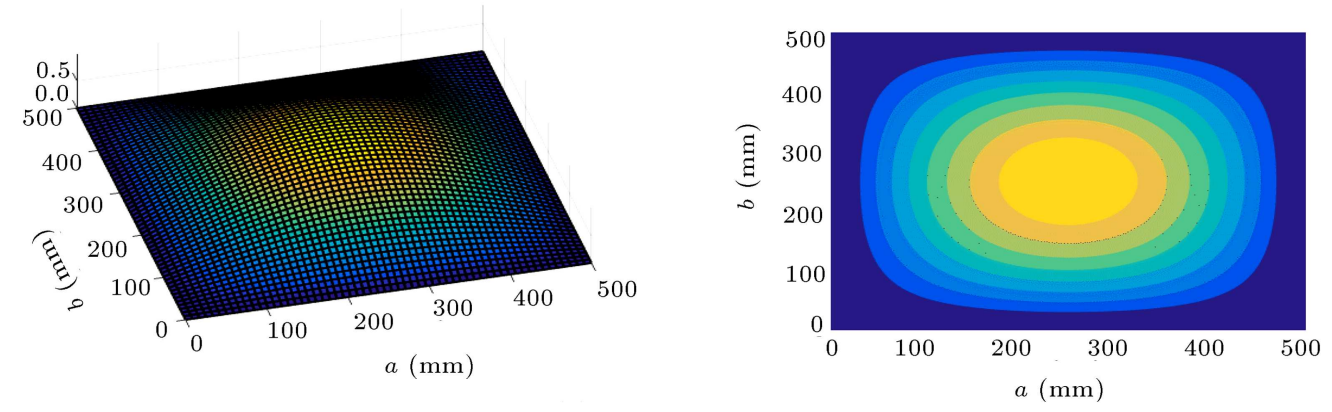

(a) In Example 1
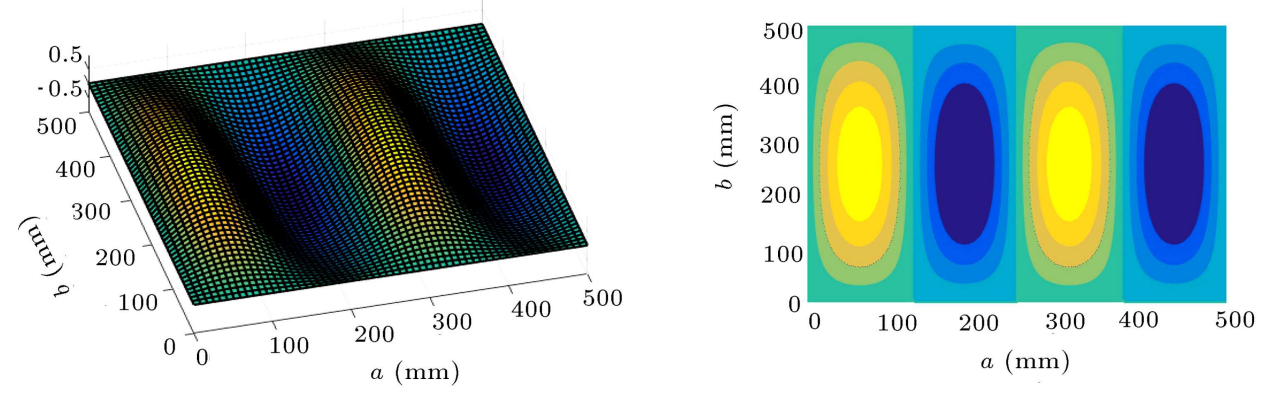

(b) In Example 3

Figure 2. Deformation caused by the buckling of the composite plate.

is considered. The properties of composite materials are given as $E_{1}=4 \times 10^{7} \mathrm{MPa}, E_{2}=1 \times 10^{6}$ $\mathrm{MPa}, G_{12}=6 \times 10^{5} \mathrm{MPa}$, and $\nu_{12}=0.25$. All optimization problems consider that the plies have the same thickness of $0.125 \mathrm{~mm}$. For numerical example, we consider a rectangular composite plate with dimensions $b=500 \mathrm{~mm}, a=500 \mathrm{~mm}$, and $a=3000 \mathrm{~mm}$. The plate has four layers with stacking sequence $[30 \backslash-30 \backslash-30 \backslash 30]$. The laminated composite plate has simple support and semi-clamped support $\left(k_{r}=0\right.$ and $\left.1 \times 10^{9}\right)$. Table 3 and Figure 2 show the results of buckling analysis. The results point to a good correlation between the outcome of the present method and that of ABAQUS software [44].

\subsection{Optimization by ( $G A)$}

By using the proposed method that has been validated in the previous subsection, this subsection estimates the optimum fiber orientation angles of laminated plates employing the GA approach. The aim is to maximize the buckling load capacity of laminated plates considering the orientation $(\theta)$ as design variables. To capture the effect of boundary support of plates, three different boundary conditions are assumed by changing 
the boundary stiffness ratio (i.e., $k_{r}$ as shown in Figure $1(\mathrm{c}))$ as follows: simple support, semi-clamped support, and clamped support. 4-ply $[\theta /-\theta /-\theta / \theta]$ symmetric laminates at several aspect ratios $(a / b), \alpha, K_{W}$, and $K_{S}$ are considered. The aim of the optimization is that the capacity of the buckling load is maximized using GA, while the design variable is the fiber orientation, $\theta$. Thus, it should find an optimal orientation $\theta$ for various models. Overlaying the plies as negative and positive is in accordance with Refs. [24,45]. The mentioned authors concluded that this type of stacking sequence enjoyed the best performance. In the analysis, the elastic lamina's properties are considered as follows:

$$
\begin{aligned}
& \frac{E_{1}}{E_{2}}=40, \quad \frac{G_{12}}{E_{2}}=\frac{G_{13}}{E_{2}}=0.6, \quad \frac{G_{23}}{E_{2}}=0.5, \\
& \nu_{12}=\nu_{13}=0.25 .
\end{aligned}
$$

The ratio of the length of $b$ to the thickness of the plate is considered $b / h=10$.

\subsubsection{The plate with simple support}

At first, a laminated composite plate with simple support $\left(k_{r}=0\right)$ is considered. Table 4, Figure 3, and Figure 4 show the optimal orientation $(\theta)$ of the

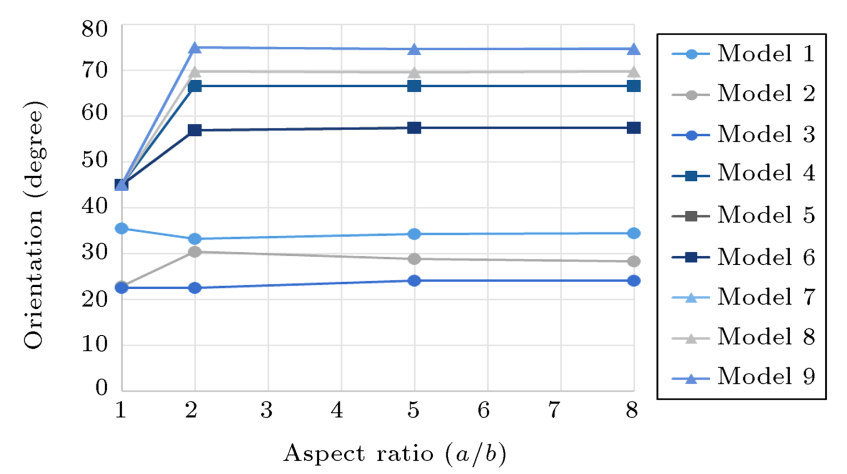

Figure 3. Optimal orientation $\theta$ of the plate with simple support on the elastic foundation.

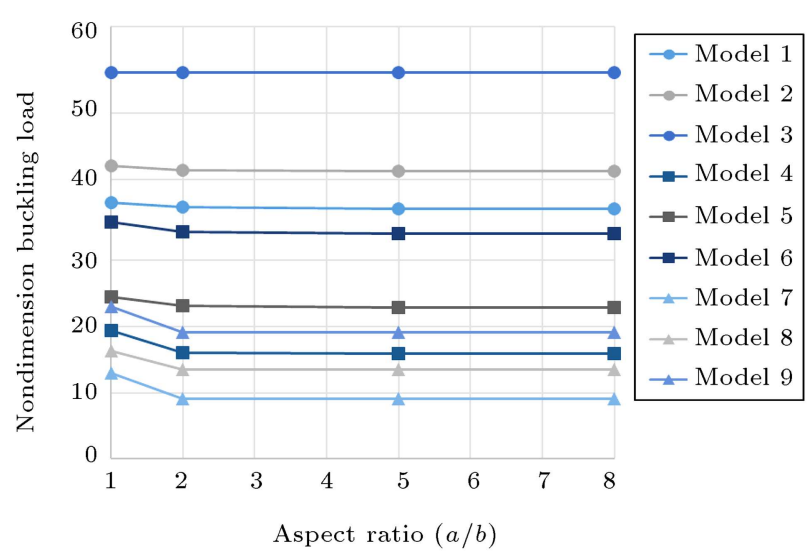

Figure 4. Non-dimensional buckling load factors of the plate with simple support on the elastic foundation.

plate at several aspect ratios $(a / b), \alpha, K_{W}$, and $K_{S}$. As can be seen, if there is uniaxial in-plane loading $(\alpha=0)$, the optimal orientation for all models will be below $35^{\circ}$. It is obvious that the plies tend to be located in the loading direction. Upon adding Winkler foundation, the optimal orientation decreases. The optimal orientation undergoes a significant reduction when Pasternak foundation is added. At aspect ratios greater than 1, changes in the optimal orientation are negligible.

If there is biaxial in-plane loading ( $\alpha=1$ and $\alpha=2$ ), the optimal orientation tends to increase. At the aspect ratio $(a / b)$ equal to 1 under biaxial in-plane loading, in situations with and without the foundation, the optimal orientation $(\theta)$ is $45^{\circ}[24,46,47]$. The orientation increases at the aspect ratios greater than 1. However, at the aspect ratios between 2 and 8 , the orientation does not change. At $\alpha=1$, the foundations cause a decrease in the optimal orientation, i.e., approximately $57^{\circ}$. However, at $\alpha=2$, the foundations have a minor effect on the optimal orientation.

According to Table 5 and Figure 4, with an increase in $\alpha$, the buckling load decreases. In addition, by adding foundations (especially Pasternak foundation),

\begin{tabular}{|c|c|c|c|c|c|c|c|}
\hline \multicolumn{4}{|c|}{ Aspect ratio } & \multirow{2}{*}{1} & \multirow{2}{*}{2} & \multirow{2}{*}{5} & \multirow{2}{*}{8} \\
\hline Case & $\alpha$ & $\boldsymbol{K}_{W}$ & $\boldsymbol{K}_{S}$ & & & & \\
\hline Model 1 & 0 & 0 & 0 & 35.54 & 33.18 & 34.22 & 34.42 \\
\hline Model 2 & 0 & 100 & 0 & 22.94 & 30.41 & 28.79 & 28.30 \\
\hline Model 3 & 0 & 100 & 10 & 22.56 & 22.56 & 24.03 & 24.17 \\
\hline Model 4 & 1 & 0 & 0 & 45.00 & 66.54 & 66.65 & 66.66 \\
\hline Model 5 & 1 & 100 & 0 & 45.00 & 56.99 & 57.45 & 57.50 \\
\hline Model 6 & 1 & 100 & 10 & 45.00 & 56.99 & 57.45 & 57.50 \\
\hline Model 7 & 2 & 0 & 0 & 45.00 & 75.06 & 74.71 & 74.77 \\
\hline Model 8 & 2 & 100 & 0 & 45.00 & 69.66 & 69.66 & 69.66 \\
\hline Model 9 & 2 & 100 & 10 & 45.00 & 74.99 & 74.64 & 74.70 \\
\hline
\end{tabular}

Table 4. Optimal orientation $\theta$ of the plate with simple support on elastic foundation. 
Table 5. Non-dimensional buckling load factors of the plate with simple support on elastic foundation.

\begin{tabular}{|c|c|c|c|c|c|c|c|}
\hline \multicolumn{4}{|c|}{ Aspect ratio } & \multirow{2}{*}{1} & \multirow{2}{*}{2} & \multirow{2}{*}{5} & \multirow{2}{*}{8} \\
\hline Case & $\alpha$ & $\boldsymbol{K}_{W}$ & $\boldsymbol{K}_{S}$ & & & & \\
\hline Model 1 & 0 & 0 & 0 & 37.51 & 36.75 & 36.56 & 36.53 \\
\hline Model 2 & 0 & 100 & 0 & 42.02 & 41.31 & 41.18 & 41.18 \\
\hline Model 3 & 0 & 100 & 10 & 54.52 & 54.52 & 54.50 & 54.47 \\
\hline Model 4 & 1 & 0 & 0 & 19.45 & 16.04 & 15.98 & 15.97 \\
\hline Model 5 & 1 & 100 & 0 & 24.51 & 23.08 & 22.85 & 22.82 \\
\hline Model 6 & 1 & 100 & 10 & 34.51 & 33.08 & 32.85 & 32.82 \\
\hline Model 7 & 2 & 0 & 0 & 12.96 & 9.06 & 9.06 & 9.06 \\
\hline Model 8 & 2 & 100 & 0 & 16.34 & 13.50 & 13.50 & 13.50 \\
\hline Model 9 & 2 & 100 & 10 & 23.01 & 19.12 & 19.12 & 19.12 \\
\hline
\end{tabular}

Table 6. Optimal orientation $\theta$ of the plate with semi-clamped support on elastic foundation.

\begin{tabular}{|c|c|c|c|c|c|c|c|}
\hline \multicolumn{4}{|c|}{ Aspect ratio } & \multirow{2}{*}{1} & \multirow{2}{*}{2} & \multirow{2}{*}{5} & \multirow{2}{*}{8} \\
\hline Case & $\alpha$ & $K_{W}$ & $K_{S}$ & & & & \\
\hline Model 1 & 0 & 0 & 0 & 28.49 & 29.04 & 30.83 & 29.82 \\
\hline Model 2 & 0 & 100 & 0 & 22.86 & 24.74 & 24.92 & 25.50 \\
\hline Model 3 & 0 & 100 & 10 & 22.29 & 21.80 & 20.70 & 21.26 \\
\hline Model 4 & 1 & 0 & 0 & 44.54 & 60.03 & 60.15 & 60.17 \\
\hline Model 5 & 1 & 100 & 0 & 45.08 & 50.38 & 50.51 & 50.53 \\
\hline Model 6 & 1 & 100 & 10 & 45.08 & 50.38 & 50.51 & 50.53 \\
\hline Model 7 & 2 & 0 & 0 & 45.28 & 71.06 & 70.79 & 70.83 \\
\hline Model 8 & 2 & 100 & 0 & 45.93 & 65.40 & 65.42 & 65.42 \\
\hline Model 9 & 2 & 100 & 10 & 46.23 & 71.04 & 70.77 & 70.82 \\
\hline
\end{tabular}

the buckling load increases. Increasing the aspect ratio has a minor effect on the buckling load variations; however, increasing the aspect ratio causes increase in the half-wave of buckling. By assuming the same total thickness of the plate, the above results can be obtained for the plate with different layers (e.g., the plate with 8 layers).

\subsubsection{The plate with semi-clamped support}

Table 6 and Figure 5 illustrate a laminated composite plate with semi-clamped support $\left(k_{r}=1 \times 10^{9}\right)$. As shown, if there is uniaxial in-plane loading $(\alpha=0)$, the optimal orientation $\theta$ in all models is below $30^{\circ}$. Therefore, all values are less than those of the plate with simple support. In addition, variation in optimal orientation is less than that in the aspect ratio. If there is biaxial in-plane loading ( $\alpha=1$ and $\alpha=2$ ), at the aspect ratio equal to one, with and without the foundations, the optimal orientation $\theta$ is $45^{\circ}$. However, at the aspect ratios greater than 1, under biaxial loading, the optimal orientation increases. The optimal orientation in the plate with semi-clamped support is significantly less than that in the plate with simple

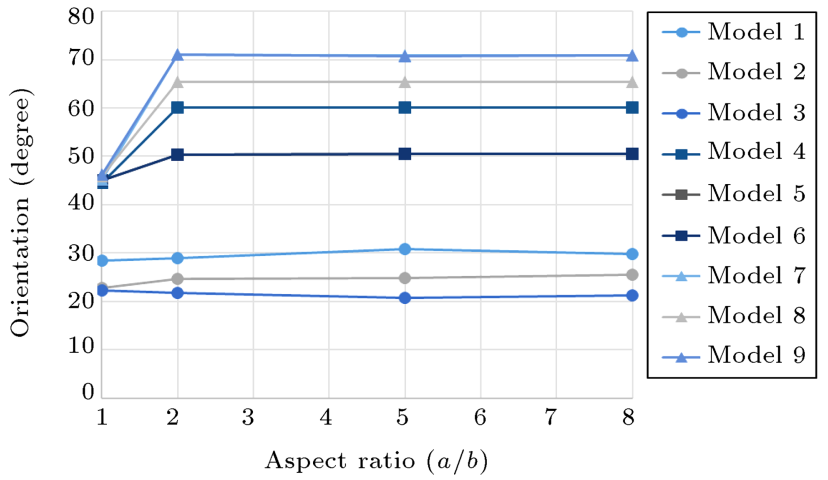

Figure 5. Optimal orientation $\theta$ of the plate with semi-clamped support on elastic foundation.

support. According to Table 7, in all the models, the buckling load on the plate with semi-clamped support is somewhat more than that on the plate with simple support.

3.2.3. The plate with clamped support

Table 8 and Figure 6 show a laminated composite plate with clamped support $\left(k_{r}=1 \times 10^{12}\right)$. As 
Table 7. Non-dimensional buckling load factors of the plate with semi-clamped support on elastic foundation.

\begin{tabular}{|c|c|c|c|c|c|c|c|}
\hline \multicolumn{4}{|c|}{ Aspect ratio } & \multirow{2}{*}{1} & \multirow{2}{*}{2} & \multirow{2}{*}{5} & \multirow{2}{*}{8} \\
\hline Case & $\alpha$ & $\boldsymbol{K}_{W}$ & $\boldsymbol{K}_{S}$ & & & & \\
\hline Model 1 & 0 & 0 & 0 & 40.66 & 39.45 & 39.44 & 39.44 \\
\hline Model 2 & 0 & 100 & 0 & 43.68 & 43.63 & 43.43 & 43.42 \\
\hline Model 3 & 0 & 100 & 10 & 56.68 & 56.68 & 56.61 & 56.61 \\
\hline Model 4 & 1 & 0 & 0 & 21.21 & 19.43 & 19.38 & 19.37 \\
\hline Model 5 & 1 & 100 & 0 & 26.16 & 25.93 & 25.89 & 25.89 \\
\hline Model 6 & 1 & 100 & 10 & 36.16 & 35.93 & 35.89 & 35.89 \\
\hline Model 7 & 2 & 0 & 0 & 14.03 & 11.09 & 11.09 & 11.08 \\
\hline Model 8 & 2 & 100 & 0 & 17.31 & 15.45 & 15.45 & 15.45 \\
\hline Model 9 & 2 & 100 & 10 & 23.93 & 21.10 & 21.10 & 21.10 \\
\hline
\end{tabular}

Table 8. Optimal orientation $\theta$ of the plate with clamped support on elastic foundation.

\begin{tabular}{|c|c|c|c|c|c|c|c|}
\hline \multicolumn{4}{|c|}{ Aspect ratio } & \multirow{2}{*}{1} & \multirow{2}{*}{2} & \multirow{2}{*}{5} & \multirow{2}{*}{8} \\
\hline Case & $\alpha$ & $\boldsymbol{K}_{W}$ & $\boldsymbol{K}_{S}$ & & & & \\
\hline Model 1 & 0 & 0 & 0 & 26.75 & 29.32 & 29.90 & 30.39 \\
\hline Model 2 & 0 & 100 & 0 & 26.75 & 26.75 & 26.72 & 26.33 \\
\hline Model 3 & 0 & 100 & 10 & 20.23 & 21.40 & 21.32 & 21.40 \\
\hline Model 4 & 1 & 0 & 0 & 53.75 & 52.60 & 52.18 & 52.10 \\
\hline Model 5 & 1 & 100 & 0 & 48.62 & 47.31 & 46.78 & 47.04 \\
\hline Model 6 & 1 & 100 & 10 & 48.62 & 47.31 & 46.78 & 47.04 \\
\hline Model 7 & 2 & 0 & 0 & 54.72 & 63.89 & 64.07 & 63.93 \\
\hline Model 8 & 2 & 100 & 0 & 54.73 & 60.10 & 60.22 & 60.27 \\
\hline Model 9 & 2 & 100 & 10 & 54.74 & 65.11 & 65.31 & 65.42 \\
\hline
\end{tabular}

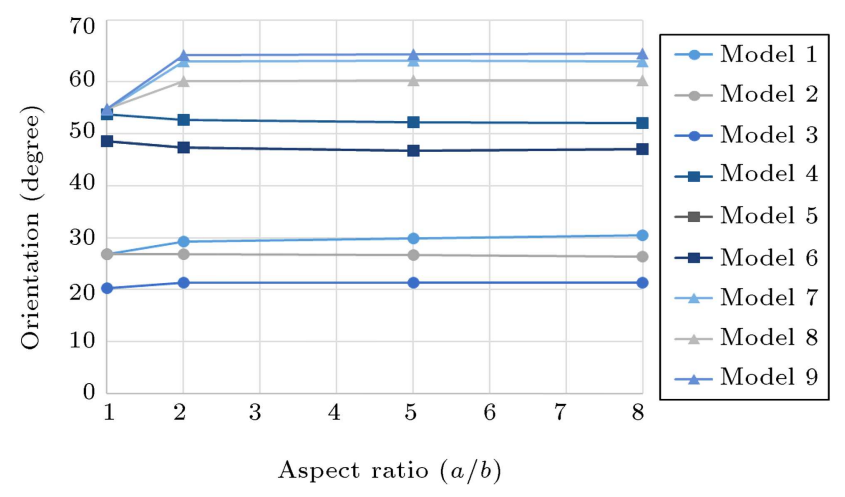

Figure 6. Optimal orientation $\theta$ of the plate with clamped support on elastic foundation.

shown, if there is uniaxial in-plane loading $(\alpha=0)$, the optimal orientation $(\theta)$ in all models will be below $30^{\circ}$. Therefore, the values are similar to those of the plate with semi-clamped support. In the plate under biaxial loading, the optimal orientation in all models is higher than $45^{\circ}$. In the models with $\alpha=1$, the optimal orientation variations versus the aspect ratio ones are almost negligible.

In various supporting conditions, when $\alpha=2$ and the aspect ratio is greater than 1, the optimal orientation is higher than $60^{\circ}$. It is shown that the

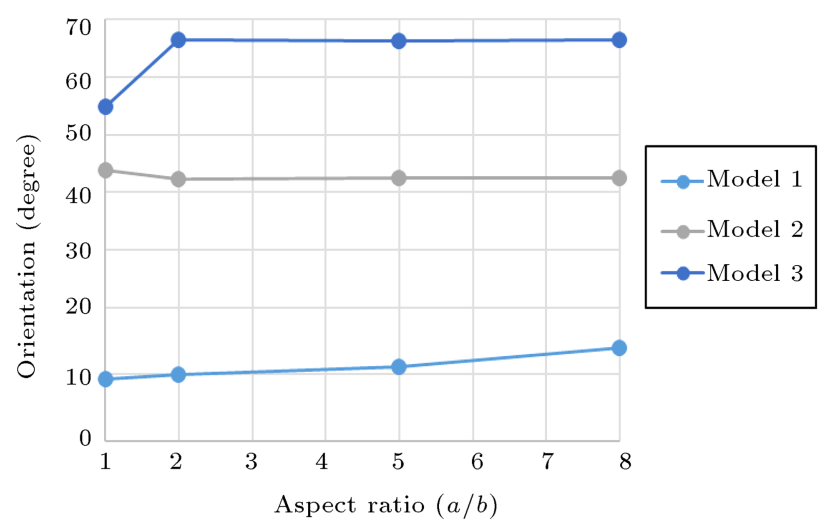

Figure 7. Optimal orientation $\theta$ of the plate with clamped support on elastic foundation.

ply orientation tends to be located in the $y$ direction, because in the long plate, the effect of in-plane loading in the $y$ direction is more significant. According to Table 9 , in all models, the buckling load on the plate with clamped support is quite greater than that on the plates with simple support and semi-clamped support.

For example, a clamped supported laminated composite plate $\left(k_{r}=1 \times 10^{12}\right)$ with different foundation stiffness values $\left(K_{W}=200\right.$ and $\left.K_{S}=20\right)$ is considered. The results are presented in Figures $7-8$ 
Table 9. Non-dimensional buckling load factors of the plate with clamped support on elastic foundation.

\begin{tabular}{|c|c|c|c|c|c|c|c|}
\hline \multicolumn{4}{|c|}{ Aspect ratio } & \multirow{2}{*}{1} & \multirow{2}{*}{2} & \multirow{2}{*}{5} & \multirow{2}{*}{8} \\
\hline Case & $\alpha$ & $\boldsymbol{K}_{W}$ & $\boldsymbol{K}_{S}$ & & & & \\
\hline Model 1 & 0 & 0 & 0 & 42.37 & 42.28 & 42.11 & 42.12 \\
\hline Model 2 & 0 & 100 & 0 & 44.90 & 44.90 & 44.90 & 44.90 \\
\hline Model 3 & 0 & 100 & 10 & 57.72 & 57.54 & 57.55 & 57.54 \\
\hline Model 4 & 1 & 0 & 0 & 24.91 & 24.88 & 24.87 & 24.86 \\
\hline Model 5 & 1 & 100 & 0 & 28.98 & 28.85 & 28.79 & 28.79 \\
\hline Model 6 & 1 & 100 & 10 & 38.98 & 38.85 & 38.79 & 38.79 \\
\hline Model 7 & 2 & 0 & 0 & 15.86 & 15.52 & 15.51 & 15.51 \\
\hline Model 8 & 2 & 100 & 0 & 18.62 & 18.50 & 18.50 & 18.50 \\
\hline Model 9 & 2 & 100 & 10 & 24.99 & 24.57 & 24.56 & 24.56 \\
\hline
\end{tabular}

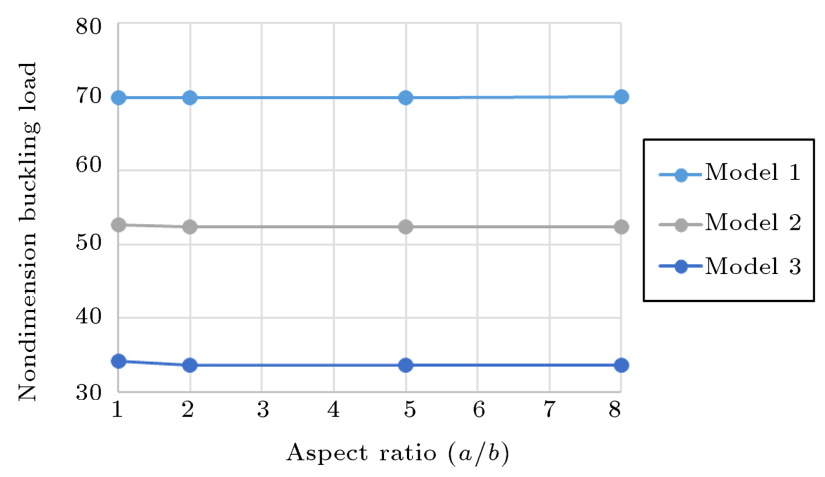

Figure 8. Non-dimensional buckling load factors of the plate with simple support on elastic foundation.

Table 10. Optimal orientation $\theta$ of the plate with clamped support on elastic foundation.

\begin{tabular}{cccccc}
\hline \multicolumn{2}{c}{ Aspect ratio } & \multirow{2}{*}{$\mathbf{1}$} & $\mathbf{2}$ & $\mathbf{5}$ & $\mathbf{8}$ \\
\cline { 1 - 2 } Case & $\boldsymbol{\alpha}$ & & & & \\
\hline Model 1 & 0 & 9.08 & 9.8 & 11.23 & 14.47 \\
Model 2 & 1 & 43.74 & 42.23 & 42.48 & 42.55 \\
Model 3 & 2 & 54.76 & 66.35 & 66.25 & 66.41 \\
\hline
\end{tabular}

Table 11. Non-dimensional buckling load factors of the plate with clamped support on elastic foundation.

\begin{tabular}{cccccc}
\hline \multicolumn{2}{c}{ Aspect ratio } & \multirow{2}{*}{$\mathbf{1}$} & $\mathbf{2}$ & $\mathbf{5}$ & $\mathbf{8}$ \\
\cline { 1 - 4 } Case & $\boldsymbol{\alpha}$ & & & & \\
\cline { 1 - 5 } Model 1 & 0 & 69.82 & 69.84 & 69.91 & 69.98 \\
Model 2 & 1 & 52.68 & 52.4 & 52.32 & 52.31 \\
Model 3 & 2 & 34.12 & 33.61 & 33.59 & 33.59 \\
\hline
\end{tabular}

and Tables 10-11. As shown, if there is uniaxial inplane loading $(\alpha=0)$, the optimal orientation in all models is below $15^{\circ}$. Therefore, the values are quite lower than those of the clamped supported plate with lower foundation stiffness. In the plate under biaxial loading, the optimal orientation in all models is higher than $45^{\circ}$. In the models with $\alpha=1$, the optimal orientation variation versus the changes in different aspect ratios is almost negligible (i.e., it is similar to that of the clamped supported plate with lower foundation stiffness).

In various supporting conditions, when $\alpha=2$ and the aspect ratio is greater than 1, the optimal orientation is higher than $65^{\circ}$. According to Table 10 , high foundation stiffness increases the buckling load.

\section{Numerical post-buckling results}

\subsection{Comparison of the analytical solutions for the post-buckling analysis}

This subsection illustrates the accuracy of the present analytical solutions for the load-deflection curves of clamped supported laminated composite plates with configurations $(90 / 0 / 45 /-45)$ and $(67.5 /-67.5)$ under shear loads such that all individual laminate layers have the same thicknesses of $0.3 \mathrm{~mm}$ and $0.6 \mathrm{~mm}$, respectively. Also, it is assumed that the material properties of all lamina are the same. In the analysis, elastic lamina properties are assumed to be:

$$
\begin{aligned}
& E_{11}=113 \mathrm{GPa}, E_{22}=9 \mathrm{GPa}, G_{12}=3.82 \mathrm{GPa}, \\
& \nu_{12}=0.302
\end{aligned}
$$

Finite element software is used to validate the analytical solution. The analytical and FEM curves are given in Figures 9 and 10 . The results show that the analytical curves enjoy positive agreement with the FEM curves in the post-buckling process.

\subsection{Optimization scheme}

In the second subsection, the optimum stacking sequences of unsymmetrical rotationally-restrained laminated composite plates under shear loading are presented. In the optimization process, the number of generations and the number of the runs are considered as 100 and 200 for GA algorithm, respectively. Figure 11 shows the load-deflection curves of three 


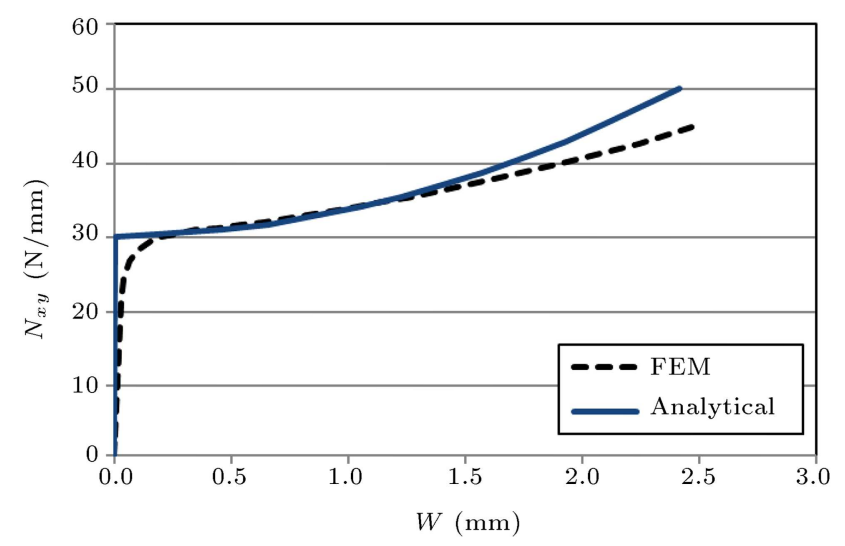

Figure 9. Laminated composite plates with configurations $(90 / 0 / 45 /-45)$.

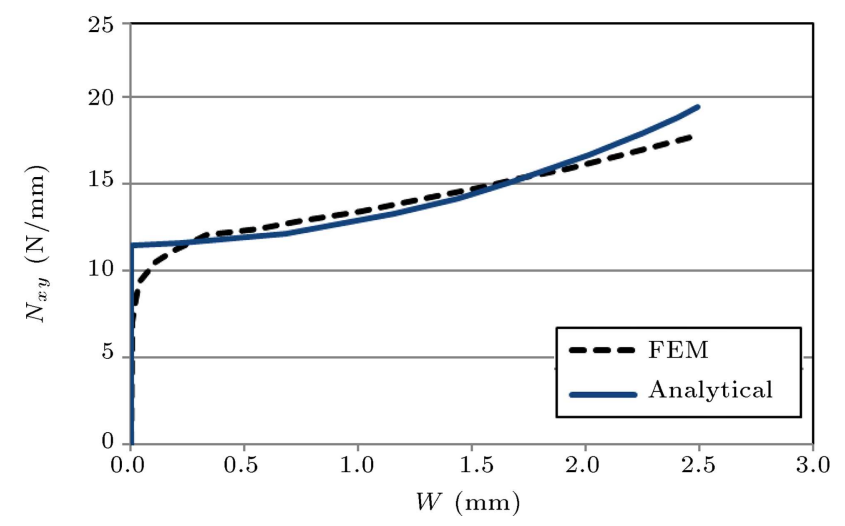

Figure 10. Laminated composite plates with configurations $(67.5 /-67.5)$. kinds of laminates with different torsion stiffnesses $(\bar{K}=0,10,100)$ and different numbers of plies. In Table 12, the optimal stacking sequence of the plate is given for three kinds of laminates with different torsion stiffnesses. It can be observed that the bearing capacity is higher than that of the laminate with configurations $(90 / 0 / 45 /-45)$. This increase is estimated to be approximately $80 \%$, demonstrating that the optimal stacking sequence is very efficient. In addition, an increase in edge torsion stiffness results in increasing the bearing capacity of the laminates. On the other hand, according to the results, as the number of layer increases, the load-deflection curves become almost the same. These results can be of value to the design en gineers of composite plate-like structures. In another example, width $b$ is considered $500 \mathrm{~mm}$ and the other properties of the above example remain the same. Figure 12 shows the load-deflection curves of new laminates with different torsion stiffnesses $(\bar{K}=0,10,100)$ and different numbers of plies. In Table 13, the optimal stacking sequence of the plate is given for three kinds of laminates with different torsion stiffnesses. It can be observed that the increase of the width has not influenced the optimal stacking sequence. However, the above increase results in reducing the bearing capacity of the plate. In addition, an increase in edge torsion stiffness leads to increase in the bearing capacity of the laminates. On the other hand, based on the results, as the number of layers increases, the load-deflection curves become almost the same.

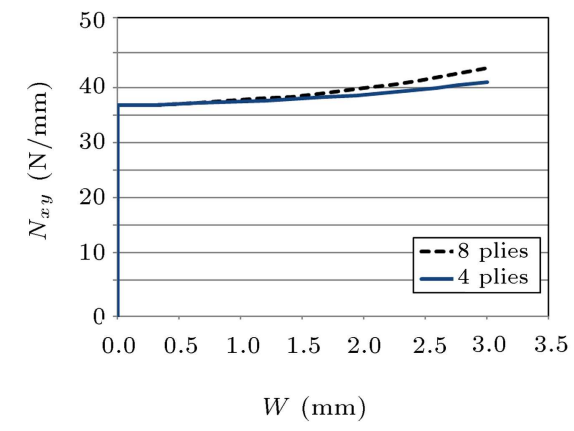

(a) $\bar{K}=0$

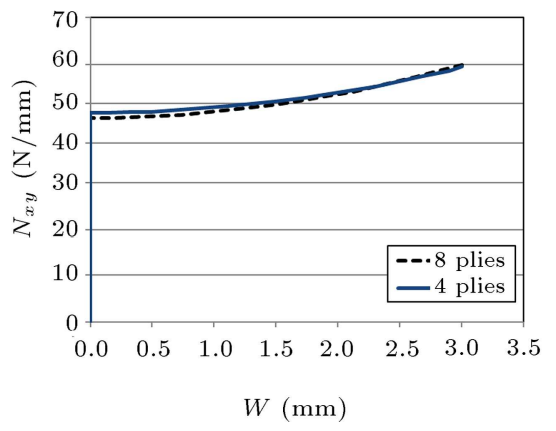

(b) $\bar{K}=10$

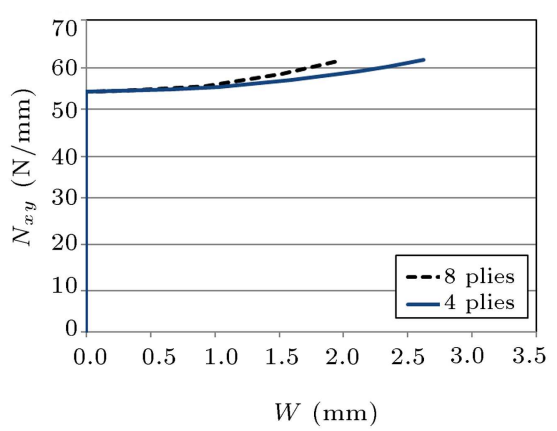

(c) $\bar{K}=100$

Figure 11. Load-deflection curves of laminates with different number of plies for Model 1.

Table 12. Optimum stacking sequence from Genetic Algorithm (GA) for Model 1.

\begin{tabular}{ccl}
\hline Number of plies & $\overline{\boldsymbol{K}}$ & Optimal stacking sequence \\
\hline 4 & 0 & {$[-64 /-63 /-64 /-65]$} \\
4 & 10 & {$[-65 /-61 /-64 /-65]$} \\
4 & 100 & {$[-59 / 90 /-51 /-58]$} \\
8 & 0 & {$[-65 /-63 /-61 /-48 / 54 /-67 /-63 /-63]$} \\
8 & 10 & {$[-64 /-66 /-61 /-59 /-52 /-65 /-69 /-69]$} \\
8 & 100 & {$[-58 /-60 / 75 / 76 /-11 /-47 /-64 /-58]$} \\
\hline
\end{tabular}




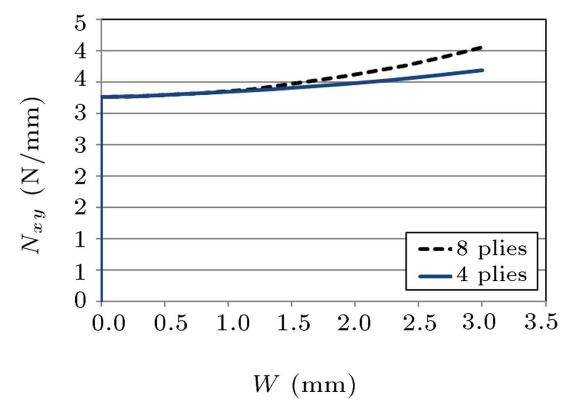

(a) $\bar{K}=0$

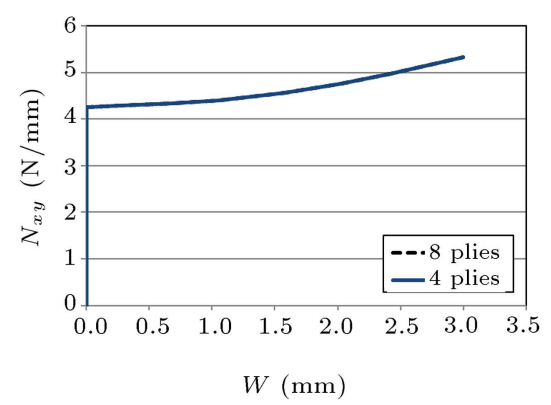

(b) $\bar{K}=10$

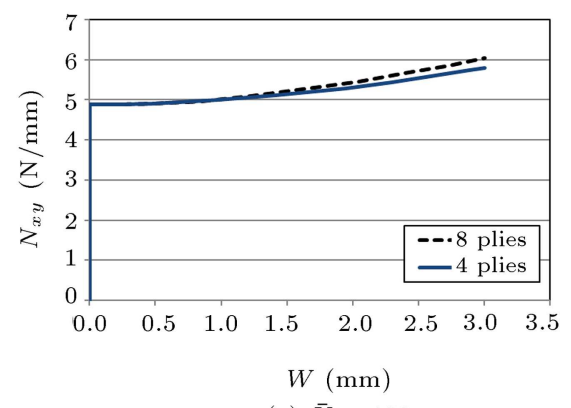

(c) $\bar{K}=100$

Figure 12. Load-deflection curves of laminates with different number of plies for Model 2.

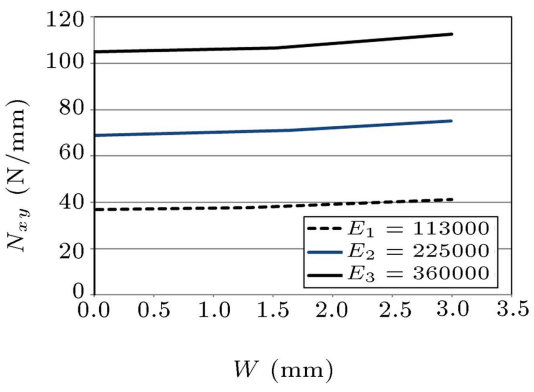

(a) $\bar{K}=0$

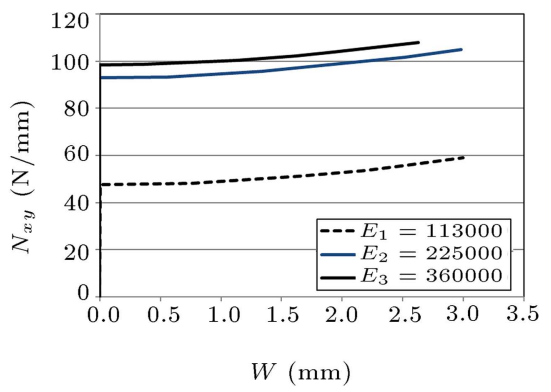

(b) $\bar{K}=10$

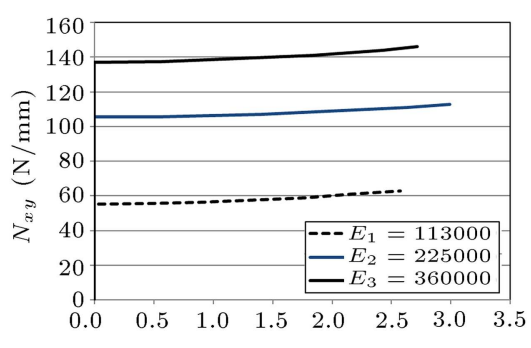

$W(\mathrm{~mm})$

(c) $\bar{K}=100$

Figure 13. Load-deflection curves of laminates with different number of plies with different moduli of elasticity.

Table 13. Optimum stacking sequence from Genetic Algorithm (GA) for Model 2.

\begin{tabular}{ccl}
\hline Number of plies & $\overline{\boldsymbol{K}}$ & \multicolumn{1}{c}{ Optimal stacking sequence } \\
\hline 4 & 0 & {$[-64 /-62 /-64 /-65]$} \\
4 & 10 & {$[-65 /-63 /-63 /-65]$} \\
4 & 100 & {$[-59 / 81 /-61 /-57]$} \\
8 & 0 & {$[-63 /-63 /-67 / 62 / 50 /-68 /-68 /-63]$} \\
8 & 10 & {$[-67 /-62 /-70 /-59 /-70 /-60 /-63 /-65]$} \\
8 & 100 & {$[-56 /-66 /-88 /-86 /-25 /-57 /-54 /-61]$} \\
\hline
\end{tabular}

As the last example, the effects of the change in the modulus of elasticity $E_{1}$ on the bearing capacity of the laminates are examined. Three different moduli of elasticity $E_{1}$ are considered and the other properties of the first example remain the same. Figure 13 shows the load-deflection curves of new laminates with different torsion stiffnesses $(\bar{K}=0,10,100)$ and different moduli of elasticity $E_{1}$. In Table 14, the optimal stacking sequence of the plate is given for three kinds of laminates with different torsion stiffnesses. It can be observed that an increase in the modulus of elasticity $E_{1}$ has no significant influence on the optimal stacking sequence. However, increase in the modulus of elasticity $E_{1}$ results in increasing the bearing capacity of the plate.
Table 14. Optimum stacking sequence from Genetic Algorithm (GA) with different moduli of elasticity.

\begin{tabular}{ccl}
\hline$\overline{\boldsymbol{K}}$ & $\boldsymbol{E}_{\mathbf{1}}(\mathbf{G P A})$ & Optimal stacking sequence \\
\hline 0 & 113 & {$[-65 /-64 /-63 /-64]$} \\
0 & 225 & {$[-67 /-68 /-66 /-69]$} \\
0 & 360 & {$[-70 /-69 /-68 /-71]$} \\
10 & 113 & {$[-65 /-63 /-66 /-65]$} \\
10 & 225 & {$[-61 /-63 /-88 /-56]$} \\
10 & 360 & {$[-64 / 78 / 61 /-44]$} \\
100 & 113 & {$[-60 /-62 / 82 /-56]$} \\
100 & 225 & {$[-49 /-69 /-55 /-53]$} \\
100 & 360 & {$[-55 / 67 /-32 /-46]$} \\
\hline
\end{tabular}




\section{Conclusion}

Identification of buckling characteristics of laminated composite plates is a beneficial tool that captures and assesses the performance of composite plates under biaxial and uniaxial loading. Upon finding the updated buckling characteristics of plates, it is possible to obtain their maximum buckling loading capacity. To evaluate the characteristics better, the studied laminated plates need to be analyzed precisely considering not only the characteristics of composite plates but also the boundary condition characteristics. Thus, the current study employed the new modified algorithm based on Genetic Algorithm (GA) to maximize the buckling load considering optimization of the fiber orientations and different boundary supported conditions. The results of the present study showed that if there was uniaxial in-plane loading $(\alpha=0)$, the optimal orientation in all the models would be below $35^{\circ}$. It is obvious that under this condition, the plies tend to be located in the loading direction. By adding the elastic foundation, especially Pasternak foundation, the optimal orientation decreased in all boundary conditions. At an aspect ratio greater than 1 under uniaxial in-plane loading, the optimal orientation variation was almost negligible.

For the plates under biaxial in-plane loading $(\alpha=$ 1 and $\alpha=2$ ) at the aspect ratios equal to 1 and with and without the foundation, the optimal orientation tended to be almost $45^{\circ}$ for all boundary conditions. However, in the plates with clamped boundary conditions, under the above-mentioned situations, the optimal orientation tended to be $55^{\circ}$ approximately.

Furthermore, based on the results, when the number of layers on the laminated plates increased, insignificant effects were determined in terms of the capacity of buckling load. However, in post-buckling behavior, the plates with many layers had the highest convergence rate.

Under biaxial in-plane loading at aspect ratios greater than 1 and with and without the foundation, the optimal orientation was greater than $45^{\circ}$; however, the clamped support and Pasternak foundation caused a minor decrease in the optimal orientation.

It can be observed that the bearing capacity of the laminate with the optimal stacking sequence was higher (approximately 80\%) than that of the laminate with the normal stacking sequence. On the other hand, based on the results, as the number of layers increased, the load-deflection curves became almost the same. It was observed that the increase of the width did not affect the optimal stacking sequence. In addition, an increase in the edge torsion stiffness and the modulus of elasticity (EI) resulted in increasing the bearing capacity of the laminates.

\section{References}

1. Xu, Y., Zhu, J., Wu, Z., et al. "A review on the design of laminated composite structures: constant and variable stiffness design and topology optimization", Advanced Composites and Hybrid Materials, 1(3), pp. 460-477 (2018).

2. Shokrollahi, S. and Shafaghat, S. "A global Ritz formulation for the free vibration analysis of hybrid metal-composite thick trapezoidal plates", Scientia Iranica, 23(1), pp. 249-259 (2016).

3. Afsharmanesh, B., Ghaheri, A., and Taheri-Behrooz, F. "Buckling and vibration of laminated composite circular plate on Winkler-type foundation", Steel and Composite Structures, 17(1), pp. 1-19 (2014).

4. Fekrar, A., El Meiche, N., Bessaim, A., et al. "Buckling analysis of functionally graded hybrid composite plates using a new four variable refined plate theory", Steel and Composite Structures, 13(1), pp. 91-107 (2012).

5. Bouderba, B., Houari, M.S.A., and Tounsi, A. "Thermomechanical bending response of FGM thick plates resting on Winkler-Pasternak elastic foundations", Steel and Composite Structures, 14(1), pp. 85-104 (2013).

6. Bloomfield, M.W., Diaconu, C.G., and Weaver, P.M. "On feasible regions of lamination parameters for layup optimization of laminated composites", Proceedings of the Royal Society A: Mathematical, Physical and Engineering Sciences, 465(2104), pp. 1123-1143 (2009).

7. Potgieter, E. and Stander, N. "The genetic algorithm applied to stiffness maximization of laminated plates: review and comparison", Structural Optimization, 15(3-4), pp. 221-229 (1998).

8. Ghiasi, H., Fayazbakhsh, K., Pasini, D., et al. "Optimum stacking sequence design of composite materials Part II: Variable stiffness design", Composite Structures, 93(1), pp. 1-13 (2010).

9. Haftka, R.T. and Walsh, J.L. "Stacking-sequence optimization for buckling of laminated plates by integer programming", AIAA Journal, 30(3), pp. 814-819 (1992).

10. Shokrani, M.H., Karimi, M., Tehrani, M.S., et al. "Buckling analysis of double-orthotropic nanoplates embedded in elastic media based on non-local twovariable refined plate theory using the GDQ method", Journal of the Brazilian Society of Mechanical Sciences and Engineering, 38(8), pp. 2589-2606 (2016).

11. Shahraki, H., Farhatnia, F., and Raeesi, M. "An exact solution for stability analysis of orthotropic rectangular thin plate under biaxial nonlinear in-plane loading resting on Pasternak foundation", Journal of the Brazilian Society of Mechanical Sciences and Engineering, 39(3), pp. 953-967 (2017).

12. Lei, Z.X., Zhang, L.W., and Liew, K.M. "Buckling analysis of CNT reinforced functionally graded laminated composite plates", Composite Structures, 152, pp. $62-73$ (2016). 
13. Yu, T., Yin, S., Bui, T.Q., et al. "NURBS-based isogeometric analysis of buckling and free vibration problems for laminated composites plates with complicated cutouts using a new simple FSDT theory and level set method", Thin-Walled Structures, 101, pp. 141-156 (2016).

14. Kheirikhah, M.M. and Babaghasabha, V. "Bending and buckling analysis of corrugated composite sandwich plates", Journal of the Brazilian Society of Mechanical Sciences and Engineering, 38(8), pp. 25712588 (2016).

15. Kerr, A.D. "Elastic and viscoelastic foundation models", Journal of Applied Mechanics, 31(3), pp. 491-498 (1964).

16. Farahani, S. and Mohebkhah, A. "Seismic behavior of direct displacement-based designed eccentrically braced frames", International Journal of Engineering, 29(6), pp. 752-761 (2016).

17. Pasternak, P.L. "On a new method of an elastic foundation by means of two foundation constants", Gosudarstvennoe Izdatelstvo Literaturi po Stroitelstuve i Arkhitekture, Moscow USSR, Russia (1954).

18. Nazarimofrad, E. and Barkhordar, A. "Buckling analysis of orthotropic rectangular plate resting on Pasternak elastic foundation under biaxial in-plane loading", Mechanics of Advanced Materials and Structures, 23(10), pp. 1144-1148 (2016).

19. Nazarimofrad, E., Zahrai, S.M., and Kholerdi, S.E.S. "Effect of rotationally restrained and Pasternak foundation on buckling of an orthotropic rectangular Mindlin plate", Mechanics of Advanced Materials and Structures, 25(7), pp. 592-599 (2018).

20. Guo, H., Zhuang, X., and Rabczuk, T. "A deep collocation method for the bending analysis of Kirchhoff plate", Comput Mater Continua, 59(2), pp. 433-456 (2019).

21. Samaniego, E., Anitescu, C., Goswami, S., et al. "An energy approach to the solution of partial differential equations in computational mechanics via machine learning: Concepts, implementation and applications", Computer Methods in Applied Mechanics and Engineering, 362, p. 112790 (2020).

22. Akhavan, H., Hashemi, S.H., Taher, H.R.D., et al. "Exact solutions for rectangular Mindlin plates under in-plane loads resting on Pasternak elastic foundation. Part I: Buckling analysis", Computational Materials Science, 44(3), pp. 968-978 (2009).

23. Golmakani, M.E. and Rezatalab, J. "Nonuniform biaxial buckling of orthotropic nanoplates embedded in an elastic medium based on nonlocal Mindlin plate theory", Composite Structures, 119, pp. 238-250 (2015).

24. Topal, U. and Uzman, Ü. "Optimum design of laminated composite plates to maximize buckling load using MFD method", Thin-Walled Structures, 45(7$8)$, pp. 660-669 (2007).
25. Le-Manh, T. and Lee, J. "Stacking sequence optimization for maximum strengths of laminated composite plates using genetic algorithm and isogeometric analysis", Composite Structures, 116, pp. 357-363 (2014).

26. Vu-Bac, N., Duong, T.X., Lahmer, T., et al. "A NURBS-based inverse analysis for reconstruction of nonlinear deformations of thin shell structures", Computer Methods in Applied Mechanics and Engineering, 331, pp. 427-455 (2018).

27. Vosoughi, A.R., Darabi, A., and Forkhorji, H.D. "Optimum stacking sequences of thick laminated composite plates for maximizing buckling load using FE-GAsPSO", Composite Structures, 159, pp. 361-367 (2017).

28. Ehsani, A. and Rezaeepazhand, J. "Stacking sequence optimization of laminated composite grid plates for maximum buckling load using genetic algorithm", International Journal of Mechanical Sciences, 119, pp. 97-106 (2016).

29. Jing, Z., Fan, X., and Sun, Q. "Stacking sequence optimization of composite laminates for maximum buckling load using permutation search algorithm", Composite Structures, 121, pp. 225-236 (2015).

30. de Almeida, F.S. "Stacking sequence optimization for maximum buckling load of composite plates using harmony search algorithm", Composite Structures, 143, pp. 287-299 (2016).

31. Kaveh, A., Dadras, A., and Malek, N.G. "Buckling load of laminated composite plates using three variants of the biogeography-based optimization algorithm", Acta Mechanica, 229(4), pp. 1551-1566 (2018).

32. de Almeida, F.S. "Optimization of laminated composite structures using harmony search algorithm", Composite Structures, 221, p. 110852 (2019).

33. Serhat, G. and Basdogan, I. "Multi-objective optimization of composite plates using lamination parameters", Materials \& Design, 180, p. 107904 (2019).

34. Atri, H.R. and Shojaee, S. "Analysis of laminated composite plates based on THB-RKPM method using the higher order shear deformation plate theory", Scientia Iranica, 26, pp. 2057-2078 (2019).

35. Nguyen, P.D., Vu, Q.V., Papazafeiropoulos, G., et al. "Optimization of laminated composite plates for maximum biaxial buckling load", VNU Journal of Science: Mathematics-Physics, 36(2), pp. 1-12 (2020).

36. Jing, Z., Sun, Q., Zhang, Y., et al. "Stacking sequence optimization for maximum buckling load of simply supported orthotropic plates by enhanced permutation search algorithm", Engineering Optimization, pp. 1-20 (2020).

37. Sivanandam, S.N. and Deepa, S.N. "Genetic algorithms", In Introduction to Genetic Algorithms, pp. 15-37, Springer, Berlin, Heidelberg (2008). 
38. Yas, M.H., Ghasemi, G.M., and Shakeri, M. "Twoobjective stacking sequence optimization of a cylindrical shell using genetic algorithm", Scientia Iranica, 14(5), pp. 499-506 (2007).

39. MATLAB R2016 Software, A program for numerical computing. MathWorks (2016).

40. Kuehn, T., Pasternak, H., and Mittelstedt, C. "Local buckling of shear-deformable laminated composite beams with arbitrary cross-sections using discrete plate analysis", Composite Structures, 113, pp. 236248 (2014).

41. Setoodeh, A.R. and Karami, G. "Static, free vibration and buckling analysis of anisotropic thick laminated composite plates on distributed and point elastic supports using a 3-D layer-wise FEM" Engineering Structures, 26(2), pp. 211-220 (2004).

42. Xiang, Y., Kitipornchai, S., and Liew, K.M. "Buckling and vibration of thick laminates on Pasternak foundations", Journal of Engineering Mechanics, 122(1), pp. 54-63 (1996).

43. Kam, T.Y. and Chang, R.R. "Buckling of shear deformable laminated composite plates", Composite Structures, 22(4), pp. 223-234 (1992).

44. ABAQUS standard user's manual. Hibbitt, Karlsson and Sorensen Inc., $\mathbf{1}$ and (3), Version 6.8-1, USA (2008).

45. Almeida Jr, J.H.S., Ribeiro, M.L., Tita, V., et al. "Stacking sequence optimization in composite tubes under internal pressure based on genetic algorithm accounting for progressive damage", Composite Structures, 178, pp. 20-26 (2017).

46. Narita, Y. and Turvey, G.J. "Maximizing the buckling loads of symmetrically laminated composite rectangular plates using a layerwise optimization approach", Proceedings of the Institution of Mechanical Engineers, Part C: Journal of Mechanical Engineering Science, 218(7), pp. 681-691 (2004).

47. Le-Manh, T. and Lee, J. "Stacking sequence optimization for maximum strengths of laminated composite plates using genetic algorithm and isogeometric analysis", Composite Structures, 116, pp. 357-363 (2014).

\section{Biographies}

Sina Farahani was born in Hamedan, Iran in 1990. He is now a Visiting Researcher at Division for Structures, Materials and Geotechnics of Aalborg University, Denmark. He was a PhD Candidate of Structural Engineering at the Razi University, Kermanshah, Iran. He received his MS degree in Structural Engineering from the Malayer University, Malayer, Iran. His research interests include performance-based seismic design of structures, direct displacement-based design of structures, nonlinear dynamics analysis, soil-structure interaction effect, optimization, seismic control of structures, and buckling of laminated composite structures.

Mojtaba Fathi was born in Kermanshah. He received his BS degree from Tehran University and his MS and $\mathrm{PhD}$ degrees from Tarbiat Modares University of Tehran in 1997 and 2004, respectively. At present, he works as an Assistant Professor at the Department of Civil Engineering in Razi University. His main research interests are structural dynamics, composite materials, modern technology in structures, semi-rigid connections, steel structures, and concrete technology. He has authored more than 100 publications in journals and conferences. He has been a reviewer in some top international journals.

Ebrahim Nazarimofrad was born in Hamedan, Iran in 1985. He received his MSc in Structural Engineering from Bu-Ali Sina University, Hamedan in 2013. His main research interests are computer programming (C\# and MATLAB), structural dynamics, earthquake engineering, passive-active control of vibration, structural health monitoring, thin-walled structures, laminated composite structures, buckling and instability, reliability of structures, shape memory alloys, finite element model, soil-structure interactions, and optimization. He has authored many publications including more than 10 journals and as well as 10 conference papers. He has been a reviewer in some top international journals as well as a structural designer in a few companies. 